\title{
NOTAS SOBRE REFERÊNCIA E INTENCIONALIDADE: FREGE E HUSSERL ${ }^{1}$
}

\author{
Maria Luísa Couto Soares
}

Universidade Nova de Lisboa

As noções de intencionalidade e referência, mantêm entre si alguma proximidade, apesar de se situarem em âmbitos distintos, mas não completamente separados $-\mathrm{a}$ intencionalidade como característica intrínseca à consciência, a referência situada no registo semântico, pertencendo à própria natureza do ato de significar. Ao pensar em intencionalidade, não podemos deixar de pensar na fenomenologia de Husserl, ao pensar em referência, o interlocutor emblemático é Frege, com a célebre distinção entre sentido e referência. O que está em causa é saber como se relacionam estas duas noções, a intencionalidade como uma dimensão intrínseca à consciência, o sentido e a referência inseridos no âmbito da semântica, ou seja características próprias do significado essencialmente referencial. Se a linguagem mostra ter, até certo ponto, uma certa autonomia em relação aos atos particularès de significar, estamos perante dois estratos da própria atividade linguística: um, objetivo, universal, essencial e independente de cada ato singular de significar, que é o próprio sentido ou significado das palavras; outro que não pode deixar de depender da particularidade de cada ato, das circunstâncias subjetivas, das situações determinadas.

Tanto Frege como Husserl fizeram duras críticas ao psicologismo e rejeitaram a interferência dos condicionamentos subjetivos, particulares, no processo da significação. Mas se a crítica ao psicologismo implica e eliminação

\footnotetext{
${ }^{1}$ Não se apresentará neste ensaio uma exposição da teoria da significação nem da noção de intencionalidade em Husserl. Apenas se fará um confronto de alguns aspetos mais problemáticos da teoria da significação de Frege com Husserl. Deste confronto não se poderão atribuir a Frege teorias intencionais nem inferir que a fenomenologia possa constituir um complemento ou uma correção de alguns aspetos da analítica fregeana.
} 
do sujeito, ou melhor dos atos de compreensão e expressão de cada indivíduo que não só usa, mas vive numa determinada linguagem, então a explicação da significação torna-se problemática. Os signos linguísticos, só por si, não significam nada, ou melhor significam potencialmente na medida em que estão intrinsecamente constituídos por uma determinada direccionalidade referencial, isto é, são por natureza significativos, a sua função consiste em apontar para além de si mesmos. Mas têm de ser "ativados", por assim dizer, ou trazidos da esfera universal e objetiva dos significados 'em si' para a atividade real e concreta da linguagem em ação.

Em Frege, a introdução da ideia de sentido, além de motivada pela explicação do valor cognitivo das proposições de identidade, visa resolver e estabelecer a mediação entre o signo, na sua materialidade e a apreensão do significado. Os sentidos das palavras, frases, e da linguagem em geral, captam-se, apreendem-se, não são originados pelos atos de significar. Em que consiste este "captar", “apreender"? Capta-se algo que está para além da própria atividade significativa, da própria compreensão linguística do sujeito. Algo que é absolutamente objetivo. A preocupação de Frege por garantir o carácter objetivo do sentido, põe em çausa a compreensão da própria atividade linguística, como atividade humana, e deixa por explicar a natureza da própria capacidade de compreender, comunicar, exprimir através da linguagem.

Husserl apresenta várias formas para unificar, numa mesma teoria, as particularidades e singularidades dos atos de significar com a 'essência' e universalidade do significado. Essas várias formas foram acompanhando a própria evolução do seu pensamento e das suas conceções da fenomenologia. Em todo o caso, é a intencionalidade que subjaz e garante a objetividade e ao mesmo tempo a inevitável 'subjetividade' dos atos de significação.

A correspondência entre os dois filósofos mostra que se estabeleceu entre ambos um diálogo e um confronto, sobre alguns aspetos pontuais das suas teorias do significado bem como da rejeição de qualquer forma de psicologismo. Entre os anos 1891 e 1894, as cartas que trocaram diziam respeito ao estatuto objectivo da lógica e da matemática, à filosofia da aritmética, à teoria do número, à distinção entre Vorstellung, Sinn e Bedeutung e à teoria do conceito como referente dos predicados.

Em carta de Maio de 1891, Frege acusa a receção da Filosofia da Aritmética de Husserl, que foi objeto de uma recensão por parte de Frege, na qual atribui à obra de Husserl vestígios de psicologismo na forma de entender a teoria do número. É conhecida a repercussão que esta crítica teve em Husserl. Este reconhece a acuidade da crítica de Frege - "he hit the nail on the head", escreve Husserl a Heidegger - e em carta posterior a Frege, manifesta o apreço pelos seus Fundamentos da Aritmética: "Das muitas das obras que tive 
presentes ao escrever o meu livro, nenhuma delas foi lida e estudada por mim com mais entusiasmo que a sua"? ${ }^{2}$

O intercâmbio da correspondência entre Frege e Husserl começa, portanto, pela questão do psicologismo, acima referida, e é Husserl quem terá que rever os seus pontos de vista sobre o assunto. ${ }^{3}$

Se refiro este fato, é simplesmente para fazer notar a implacável determinação de Frege por salvaguardar a total autonomia do domínio do objetivo, ou seja, a sua universalidade e portanto a possibilidade de ser captado, apreendido por todos, que é essencial para a lógica e para a matemática. Á linguagem deverá reger-se pelas leis do pensamento, as leis lógicas, que não são'afetadas pelas condições e circunstâncias particulares da sua compreensão por parte dos indivíduos e seus entendimentos particulares.

$\Theta$ que está aqui em causa é examinar e confrontar Frege e Husserl no que diz respeito à teoria da significação. ${ }^{4}$ Alguns dos problemas, conceitos e teorias característicos do pensamento de Husserl poderiam ser elucidados confrontando-os com os de Frege. Por seu lado, estes últimos proporcionariam um bom ponto de partida para aceder a algumas ideias e textos de Husserl. ${ }^{5}$ Se isso é assim, também é certo que em muitos aspetos as ideias de Husserl (refiro-me principalmente à sua teoria da expressão) conferem uma maior amplitude a alguns conceitos de Frege, (nomeadamente aos de sentido e referência) integrando-os num contexto mais abarcante que poderá superar alguns dos impasses das teorias de Frege.

Em primeiro lugar, confrontaremos a noção de sentido (Sinn) e o seu papel na significação, em Frege, com a correspondente noção em Husserl.

${ }^{2}$ Carta de Husserl a Frege, 18.07.1891, Frege, CP, 64.

${ }^{3}$ A recensão de Frege deve ter causado em Husserl uma profunda consternação e levou-o a uma revisão completa da sua maneira de pensar. Solomon fala mesmo do "encontro traumático com Frege", (1970), "Sense and Essence: Frege and Husserl", International Philosophical Quarterly, 10, p. 380.

${ }^{4} \mathrm{O}$ primeiro autor a tentar este confronto e estabelecer uma ponte entre a fenomenologia e a filosofia analítica, foi D. Føllesdale numa pequena monografia, Husserl and Frege, 1958, Oslo, à qual se seguiram vários artigos. Em 1982, J. N. Mohanty, numa obra mais extensa, apresenta também um confronto entre Husserl e Frege, no qual defende essencialmente duas teses: 1) nega que Frege tenha tido uma influência determinante na rejeição husserliana do psicologismo; 2) defende que a posição filosófica de Frege carece de uma fundamentação fenomenológica e que Husșerl proporciona o complemento necessário para uma maior estabilidade de algumas das perspetivas de Frege. A primeira tese é certamente excessiva; a segunda, tem algum sentido no que se refere à teoria da significação de Husserl, que complementa de certo modo a de Frege, mas não parece que o pensamento de Frege careça de uma fundamentação fenomenológica. O pensamento e o trabalho de Frege e Husserl, se apresentam algumas proximidades, têm pontos de partida e objetivos muito diferentes, para se poder fazer semelhante afirmação.

${ }^{5}$ Cf. Føllesdal, "Husserl Notion of Noema", in H. L. Dreyfus (1982). 
As ambiguidades da noção de sentido, que Frege introduz em Sinn und Bedeutung e que terá repercussões em todos os escritos posteriores, ilustra bem a determinação de Frege por salvaguardar a 'objetividade', das leis do pensamento, que não podem estar sujeitas às variações subjetivas da compreensão e do conhecimento. Por outro lado, este domínio, que Frege designa como 'o objetivo não actual', com um peculiar modo de existir independentemente do conhecimento e compreensão das mentes, torna difícil dar razão do modo como a mente se relaciona com essa objetividade. A única e recorrente explicação de Frege emprega sempre a metáfora do 'captar', 'apreender', algo que transcende a própria mente e é alheio aos processos epistemológicos que permitem essa apreensão.

A noção de sentido é introduzida em Sinn und Bedeutung (SuB), ${ }^{6}$ como dissemos, para explicar o valor cognitivo de proposições de identidade do tipo $a=b$, em contraposição com o carácter tautológico de proposições do tipo $a=a$. Neste último caso, a proposição nada nos diz de novo, não tem portanto qualquer valor cognitivo. Mas no primeiro, a proposição pode traduzir uma nova descoberta, um novo conhecimento.

Duas teses se perfilam com progressiva nitidez na conceçạo fregeana de sentido:

1. O sentido tem algo que ver com o valor cognitivo de uma expressão.

2. O sentido de uma expressão complexa (proposição) é composto pelos sentidos dos seus elementos constituintes.

A primeira tese - o sentido constitui o valor cognitivo ou informativo de uma expressão - é a resposta ou a solução à questão que Frege levantara no início de $S u B$ sobre a razão da diferença de proposições de identidade do tipo " $a=a " e$ " $a=b "$ ", quanto ao seu valor informativo. Ao substituir um dos nomes por outro com a mesma referência, mas com sentido diferente, alteramos o pensamento da proposição, ou melhor, trata-se de outro pensamento.

O que se entende então por sentido de um nome próprio? Empregar um nome próprio implica, não só estabelecer uma relação semântica que associa um signo a um determinado objeto, mas apreender o nome como um modo particular de identificar esse objeto como seu referente. Dizer que dois nomes

${ }^{6}$ Antes deste ensaio de 1892, Frege utilizara já o termo Inhalt na Begriffsschrift, $\S 8$, também relacionado com a noção de identidade, uma relação entre sinais que exprime a circunstância de dois nomes ou expressões terem o mesmo conteúdo. Em carta a Husserl (CP, 63), Frege escreve que o emprego de Sinn nos $\S \S 97-103$ corresponde ao emprego mais tardio de Bedeutung. Cf. Também $\S 67$ dos Grundlagen der Arithmetik, onde, de novo está em causa a noção de identidade, que pressupõe a possibilidade de um mesmo objeto poder ser referido de vários modos, e pode ser reconhecido sob várias designações. Mas é em Über Sinn und Bedeutung. que Frege estabelece explicitamente os diferentes papéis dos dois termos. Cf. Maria Luísa Couto Soares (2001),pp. 143-148. 
têm a mesma referência, mas sentidos diferentes significa que com os dois nomes se podem associar diferentes modos de reconhecer e identificar o mesmo objeto. O sentido poderá ser considerado como o correspondente critério de_identidade associado a cada nome próprio.

Associar um critério de identidade a um nome significa possuir um meio para reconhecer o objeto designado como sendo o mesmo objeto; ou, por outras palavras, saber em que condições qualquer outro termo pode designar o mesmo objeto.

Assimilar o sentido de um nome ao critério de identidade acarreta, no entanto, algumas dificuldades para garantir, como Frege parece pretender, o seu carácter objetivo. O modo ou a via para identificar o objeto designado por um nome próprio pode variar de pessoa para pessoa, ou seja o mesmo objeto pode ser identificado segundo diferentes critérios. "Aristóteles" pode ser, para uns, identificado como o "discípulo de Platão", para outros como "o mestre de Alexandre", para outros como "o Estagirita", etc. E Frege não opõe nenhuma objeção a estas variações de sentido, desde que a referência permaneça a mesma, embora reconheça que se deverão evitar na estrutura teórica de uma ciência demonstrativa. Uma linguagem estritamente rigorosa não poderá tolerar uma oscilação de sentidos ou de critérios para identificar a referência de um nome. ${ }^{7}$

O sentido assim explicado será, no entanto, totalmente subjetivo: será captado, apreendido, como explica Frege, por qualquer pessoa que esteja suficientemente familiarizada com uma linguagem e com a totalidade de designações correspondentes a um determinado nome. ${ }^{8}$ Entendido deste modo, como a via particular através da qual cada um associa um nome a uma referência, o sentido não apresentará aquele carácter permanente, objetivo que Frege lhe pretende atribuir. Será apenas o processo subjetivo, variável de indivíduo para indivíduo, segundo o qual se apreende a utilização correcta de um nome. $\mathrm{E}$, sendo assim, o sentido deixaria de pertencer à teoria do significado como uma característica objetiva das expressões linguísticas, mas apresentar-se-ia como uma noção meramente psicológica, expressão da aprendizagem individual do uso dos nomes na linguagem. Neste caso, não é possível exigir uma determinação inequívoca do sentido: um mesmo nome próprio poderá ter tantos sentidos quantas versões assumir a sụa compreensã́o e utilização pelos vários indivíduos que o empregam na linguagem natural.

Sendo assim, como pode Frege manter que o sentido (der Sinn) de um nome próprio pode ser facilmente apreendido por qualquer pessoa? (Der Sinn eines Eigennames wird vonjedem erfaßt...) Esta afirmação poder-se-á entender

${ }^{7}$ Cf. Sinn und Bedeutung (SuB), (1967) KS, pp. 144-145 e nota 2.

${ }^{8}$ Cf. Ibid., p. 144. 
se Frege se refere aqui a um sentido habitual, mais comum. Mas, neste caso, como pode o sentido ser, por um lado, algo que se apreende inequivocamente no uso da linguagem, e por outro lado admitir tantas variações quantos os critérios de identificação do objeto designado, utilizados pelos diferentes interlocutores? $\mathrm{Ou}$, por outras palavras, como pode a diversidade e variedade de intentiones (intensiones) fixar uma unidade de sentido e garantir uma via de identificação do mesmo?

Esta versão da noção de sentido não parece, em última análise, coadunar-se com a elaboração da teoria semântica de Frege e com a sua reiterada insistência na objetividade da significação, por contraste com certos matizes no modo de expressão, dados pelo "tom", "força", noções, essas sim, totalmente subjetivas, dependentes sobretudo de impressões, ideias, associações, etc. Este mundo de representações e processos internos de associação, re-identificação, etc. é, em princípio incomunicável e utilizar estes elementos subjetivos para a elaboração de uma teoria do significado seria de fato condenar a linguagem a um insuperável solipsismo. Jamais duas pessoas diferentes poderão ter as mesmas representações, as mesmas imagens, os mesmos processos associativos. Jamais duas pessoas poderiam nos seus atos expressivos ou significativos realizar, incarnar um mesmo significado, e portanto aceder a uma instância intersubjetiva, garante da comunicabilidade.

Há uma distinção radical entre a ideia - representação, associação, critério subjetivo ou individual de identificação da referência -, e o sentido. Entre a ideia (ou representação, ou critério individual de identificação) que é subjetiva, e o objeto propriamente dito, reside o sentido.

O. "entre" é aqui fundamental: ele traduz a ambivalência da noção de sentido, que é introduzida em simultâneo com um carácter epistémico, relativo ao modo de acesso ao referente, e com um carácter fortemente "realista", objetivo, como modo de dar-se do próprio objeto de referência. Podemos pensar em duas setas - uma direcionada do sujeito para o objeto visado, a intenção do ato de consciência de..., outra direcionada do aspeto ou perspetiva do objeto que se dá se apresenta ao sujeito. A primeira confere ao sentido um carácter intencional, tanto pelo perspetivismo, pois se trata de um acesso, sempre parcial, sob um determinado aspeto, a um objeto (quer este exista quer não). Caberia aqui uma flexibilidade e um afrouxamento ṇa objetividade do sentido, que se sujeitaria à multiplicidade e variedade dos modos de acesso a um mesmo objeto, submetidos às variações das condições subjetivas. Seria difícil manter, neste caso, uma total delimitação do sentido. ${ }^{9}$ Mas a segunda,

9 Uma possível resposta será a admissão da vagueza na linguagem corrente. Frege exige recorrentemente uma estrita delimitação do significado (the sharpness requirement), e não admite nenhuma forma de vagueza sobretudo na matemática e na lógica. Lamenta que a linguagem 
parte do objeto que se apresenta, que se dá ele mesmo, não completamente, mas segundo uma certa determinação sua. Este dar-se não depende para nada da intenção da consciência subjetiva, é como um dar-se totalmente gratuito, por assim dizer. A questão que se levanta é: como se encontram, de fato estes dois "raios direccionais"? Esse é o problema que em Frege fica por resolver. A noção de sentido revela-se de um carácter paradoxalmente realista e ao mesmo tempo intencional: ${ }^{10}$ realista porque o sentido de qualquer expressão

corrente não possa apresentar-se com esse mesmo rigor, e exprime uma ideia puramente negativa da vagueza. No entanto, ao examinar a noção de sentido, Frege parece render-se à admissão de uma certa vagueza epistémica no uso dos nomes: se os sentidos possíveis, associados a um nome que refira o mesmo objeto, são inumeráveis, é difícil garantir a relação referencial, diluída numa variedade de vias que podem partir do nome para o referente, o que permite a introdução da vagueza semântica e também epistémica, pois o acesso ao objeto designado seria anulado ou obscurecido pela limitação do conhecimento que não abarca a totalidade de aspetos, propriedades e modos de dar-se do referido objeto. Quem não sabe que Alexandre Magno foi discípulo de Aristóteles, não poderá identificar o referente de "o mestre de Alexandre". Claro que neste exemplo, a vagueza semântica pode ser ultrapassada na medida em que se pode alcançar o conhecimento de Alexandre Magno ter sido discípulo. de Aristóteles. Mas a vagueza epistémica não, porque será impossivel esgotar o conhecimento total do indivíduo. Há casos em que um nome é necessariamente vago: 'O Oceano Atlântico' é vago porque não é possivel esclarecer a porção exacta de água à qual se refere o nome. A vagueza é geralmente atribuída a termos concetuais: um conceito é vago sempre que não é possivel determinar se algum ou alguns objetos caem ou não sob esse conceito. A vagueza dos nomes ou expressões que refiram um objeto, consiste em não poder determinar, para cada expressão ou nome qual o objeto que refere. Ou seja, trata-se da vagueza vista a partir do objeto para o conceito, no sentido inverso da vagueza dos termos conceptuais. A expressão funcional 'João é adulto' é um caso de vagueza, porque não é possivel delimitar com exactidão a extensão de 'ser adulto', e portanto a proposição ou é falsa ou não tem valores de verdade.

Não cabe aqui um exame da discussão sobre a vagueza em Frege. Cf. Cora Diamond (1995), cap. 5, "Frege against Fuzz", pp. 145-177; Marco Ruffino "Frege's Views on Vagueness", Manuscrito, 26(2), 2003, pp. 253-277; Gary Kemp, "Frege's Sharpness Requirement", The Philosophical Quarterly, 46(183) (April 1996), pp. 168-184, Joan Weiner, Frege in Perspective, Ithaca and London: Cornell University Press, 1990, e de T. Burge, "Frege on Sense and Linguistic Meaning" in Truth, thought, reason: essays on Frege, Oxford: Oxford University Press, 2005, Vagueness: a Reader, edited by Rosanna Keefe and Peter Smith, Cambridge Mass., The MT Press, 1996: sobretudo capítulo 10, Crispin Wright, "Language-mastery and the sorites paradox", pp. 151-174; e capítulo 13, R. M. Sainsbury, "Concepts without boundaries", pp. 251-265. Sobre vagueza cf. também Dummett, "The Wang Paradox", in Truth and other enigmas, London: Duckworth, 1978; Charles Travis, "Observation and Sorites", Mind, New Series, 94(375) (1985), pp. 345-366; T. Williamson, Vagueness, Routledge, 1994.

${ }^{10}$ Este caráter intencional do sentido constitui um dos fatores que indica uma certa afinidade entre a noção de sentido e a de intencional. Cf. G. Bar-Elli (1996), pp.16-18. A intencionalidade é um triplice critério de intencionalidade: esta é a tese de Chisholm, que submete a intencionalidade a um tratamento semântico, transferindo o exame da intencionalidade para o exame dos enunciados utilizados para descrever e atribuir intencionalidade. $O$ exame semântico de Chisholm pretende mostrar que o caráter referencial da linguagem só se pode entender a partir da intencionalidade, pois as tentativas de eliminar a intencionalidade através 
se dá independentemente da nossa capacidade de reconhecer a referência ou a verdade/falsidade dessa expressão. Intencional, porque, mesmo no caso de duas proposições analíticas equivalentes (portanto proposições para as quais o conjunto de mundos possíveis nos quais são verdadeiras/ou falsas, é exactamente o mesmo), os sentidos são diferentes. $O$ sentido não coincide afinal nem com a capacidade de reconhecer a referência ou de re-identificar o objeto designado, nem de verificar a verdade ou falsidade de uma frase, nem com a referência propriamente dita, ou com o fato de a expressão ter uma referência (pois não é condição de sentido o possuir realmente uma referência).

Um outro ponto que parece entrar em conflito com a semântica dos nomes é o seguinte: como conciliar a atribuição de sentido aos nomes (nomes próprios ou expressões que designem um objeto determinado) com o princípio do contextualismo que Frege enuncia na Introdução aos Fundamentos da Aritmética: uma palavra só tem sentido no contexto de uma proposição? Tem sido discutido o papel que este princípio desempenha no pensamento de Frege. É possível que a sua enunciação na Introdução dos Fundamentos, se justifique pela teoria do número como objeto e algo que se enuncia de um conceito, nomeadamente a sua extensão: sendo um objeto, um número não pode nunca ser um predicado, mas fazer parte de um predicado que se atribui via conceito. Os numerais que designam os números, só podem ter sentido no contexto da proposição em que ocorrem. Dizer "nesta cesta estão 10 laranjas" significa realmente que o conceito "laranjas deste cesto" subsume 10 objetos. O numeral 10 , isolado, como nome de um objeto, não tem sentido se não ocorrer integrado numa expressão com um termo concetual: enuncia algo do conceito "ser laranja deste cesto". Se Frege manteve o princípio, então a atribuição de sentido aos nomes parece contradizê-lo. Se um nome ou expressão tem sentido, isso significa que pode ser apreendido mesmo quando ocorre

da tradução de descrições intencionais para descrições condutistas e fisicalistas, falham. Neste sentido, Chisholm é um caso particular de um filósofo analítico contemporâneo que se propõe mostrar a irredutibilidade do intencional a processos naturalistas, defendendo com argumentos semânticos a peculiaridade do intencional. Embora o próprio Chisholm tenha reconhecido que os critérios de intencionalidade a partir da intencionalidade não são exclusivos de enunciados intencionais, pois há outras modalidades de enunciados intencionais que também os satisfazem, são de considerar os pressupostos que levaram Chisholm a esta transferência da intencionalidade para um exame puramente semântico: por um lado, garantir a independência da intencionalidade da existência real dos objetos, por outro lado tentar confirmar pela via linguística a tese de Brentano, a distinção entre o mental, psicológico e o físico.

Note-se ainda que, apesar da insuficiência dos critérios de Chisholm, estes aplicarse-iam plenamente aos verbos percetivos, indicando o seu carácter nitidamente intencional, mostrando a possibilidade de caracterizar a dimensão intencional da perceção, sem invocar noções como "conteúdo" percetivo ou "conteúdo" da consciência. Cf. R. Chisholm (1957), pp.170 segs. 
isoladamente. Isto é, pode, fora de qualquer contexto, realizar a sua função significativa.

A distinção radical entre concéito e objeto fica aqui patente. Por isso mesmo, um termo predicativo não refere nunca objetos. A referência de um predicado é um conceito: 'ser homem' não refere todos os homens existentes à face da terra, mas sim a propriedade ou a essência de ser homem. $O$ conceito subsume uns quantos objetos. A exigência de uma clara delimitação da extensão do conceito, que para Frege é imprescindivel numa linguagem lógica e científica, garante que um objeto cai ou não cai necessariamente sob esse conceito.

Em carta a Husserl de 24 de Maio de 1891, Frege esclarece esta relação peculiar de um termo conceptual com objetos. Enquanto os nomes referem um objeto, as proposições referem um valor de verdade (objeto lógico), o termo predicativo refere o conceito e é necessário um passo mais para alcançar os objetos. Para indicar claramente a diferença entre conceitos e objetos, Frege apresenta um esquema:

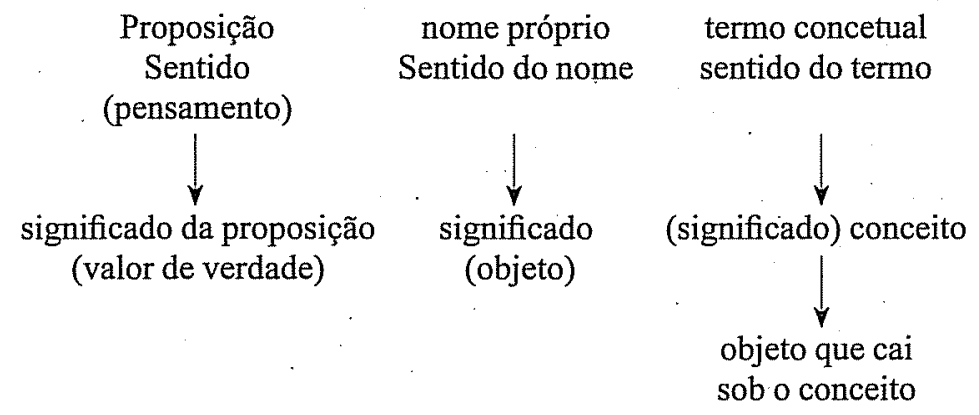

"Tracei o último passo do conceito ao objeto horizontalmente de modo a indicar que este tem lugar ao mesmo nível, que objetos e conceitos têm a mesma objetividade." [...]

"Parece-me que para si o esquema seria como este:

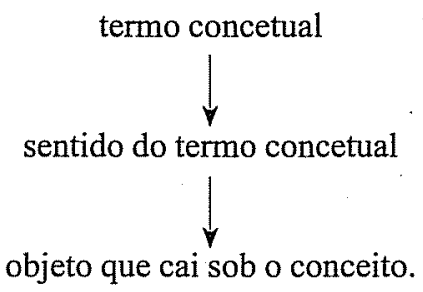

"E assim, para si entre os nomes e objetos haveria o mesmo número de passos que entre os termos conceptuais e objetos. A única diferença entre nomes próprios e termos concetuais consistiria em que os primeiros só 
refeririam um objeto e os últimos poderiam referir mais do que um. Um termo concetual cujo conceito fosse vazio teria então de ser excluído da ciểncia tal como qualquer nome próprio sem o correspondente objeto"."

É clara a ideia de Frege de que a extensão de um conceito não é constituída pelos indivíduos que lhe pertencem, mas sim pelo próprio conceito, isto é, pelo que se diz de um objeto quando é subsumido por um conceito.

Em "Ausführungen über Sinn und Bedeutung", Frege escreve explicitamente:

"Um termo concetual deve ter um sentido também, e, para o uso científico, uma referência; esta, porém não consiste nem num objeto, nem numa pluralidade de objetos, mas sim num conceito. Quanto ao conceito, por certo, pode-se perguntar novamente se um objeto, vários ou nenhum caem sob ele. Mas isto só diz diretamente respeito ao conceito". ${ }^{2}$

Esta ideia reiterada várias vezes por Frege, mostra a sua posição em relação ao critério extensional exigido por quase todos os lógicos: o seu extensionalismo consiste, essencialmente, no princípio de que em qualquer enunciado, um termo concetual pode ser substituído por outro desde que a ambos corresponda a mesma extensão. Este princípio tem um carácter meramente funcional, como uma regra da substituição dos termos salva veritate. No entanto, Frege afirma também que os conceitos podem ter extensões iguais sem que eles próprios coincidam. Isto confirma uma vez mais que não é a extensão a determinar o conceito: a intensio tem prioridade lógica sobre a extensio como Frege afirma explicitamente:

"Defendo realmente que o conceito é logicamente anterior à sua extensão; e considero trivial a tentativa de tomar a extensão de um conceito como uma classe, fazendo-a radicar, não no conceito, mas nas coisas singulares". ${ }^{13}$

Este esclarecimento mostra que $0 \cdot$ par sentido/referência não pode ser aplicado segundo uma formulação isomórfica aos nomes e aos conceitos. No caso dos termos conceptuais a questão oscila entre um intencionalismo que privilegia o sentido e um extensionalismo que opta por uma perspetiva referencialista. ${ }^{14}$

1 Carta a Husserl, 24.05.1891.

12 Nachgelassene Schriften, p. 132.

13 "Kritische Beleuchtung einiger Punkte in E. Schröder's Vorlesung über die Algebra der Logik", KS, p. 209.

14 Sobre o par extensional/intencional na lógica de Frege, cf. M. Luísa Couto Soares, (2001), pp. 110-119. 
Em Der Gedanke, ao tratar das proposições, Frege dá uma versão ultra realista da noção de sentido - o pensamento é o sentido da proposição e pode ser apreendido, captado por quem a compreenda. No entanto, esta versão deixa por explicar o modo como se pode captar o sentido, não apresenta nenhum critério sobre o reconhecimento da identidade de sentidos; a vertente epistémica do sentido, permanece totalmente na penumbra nesta versão objetiva, "ontológica" do sentido como uma "entidade" em si, pertencente a um terceiro mundo real. Frege não prescinde desta dupla caracterização do sentido: por um lado, algo de objetivo, em si mesmo considerado, não circunscrito nem limitado ao conteúdo da consciência; por outro lado, uma via, uma passagem que conduz ao referente, e, nesta medida, critério para identificar e re-identificar o objeto de referência. A noção de sentido torna-se, assim, problemática por preterir os atos de pensar e compreender às exigências de satisfazer plenamente a sua objectividade e mesmo a sua realidade. Entre pensar e pensamento há uma relação de captação, apreensão, mas o pensamento permanece extrínseco ao pensar. Frege considera os sentidos (meaning entities) como algo que medeia entre $\mathrm{o}$ ato e o objeto (se existir algum) ao qual se refere $o$ ato. Daí o problema da "ligação" que fica por resolver, isto é, remete sempre para a metáfora do captar, apreender, que não explica no entanto, a relação entre ato de pensar e pensamento. Por outras palavras, esta relação parece estabelecer-se como uma relação extrínseca ao ato de pensar, o pensamento não é nem um elemento desse ato nem se pode integrar nele. Permanece, de certo modo, independente e transcende esse mesmo ato. Não há portanto uma relação intencional, entendida como uma certa identidade entre o ato e o seu conteúdo.

$*$

A teoria de Husserl não se enfrenta com o problema da "ligação" porque os atos linguísticos são entendidos como integrados, ou tendo na base a relação intencional dos próprios atos sensoriais. A ligação com a realidade estabelece-se, portanto, antes da linguagem e a significação serem tidas em conta. ${ }^{15}$

Nas Investigações Lógicas, ${ }^{16}$ Husserl reconhece a sua proximidade da distinção fregeana entre sentido e referência. Altera a terminologia: para Husserl

${ }^{15}$ Cf. Barry Smith; "Husserl's Theory of Meaning and Reference", in Leila Haaparanta (ed.) (1994), pp.163-183: "Husserl's earlier theory is not subject to the linkage problem (and thus not subject either to the associated threat of idealism). This is because linguistic acts are conceived on this theory as being built up in every case on the basis of the low-grade intentionality of sensory acts, and the latter are guaranteed objectual correlates from the start. The linkage to reality is thereby established before meaning and language come into play."

${ }^{16}$ As citações das Investigações seguem a tradução inglesa de J. N. Findlay, Logical Investigations (LI), New York: Humanity Books, 2000. 
o termo sentido (Bedeutung) corresponde ao Sinn fregeano. ${ }^{17}$ A sua distinção entre Inhalt (conteúdo) e objeto pode ser vista como uma réplica da distinção fregeana. Portanto, o que Frege designa por Sinn, Husserl chama Bedeutung; para o termo Bedeutung de Frege, Husserl usa objeto (Gegenstand). ${ }^{18}$

Na Investigação I, Husserl distingue o conteúdo lógico que é diretamente designado nos contextos puramente lógicos e que permanece inalterado, da composição psicológica, muito variada, mudando de indivíduo para indivíduo, e variando também para o mesmo indivíduo em diferentes tempos. Cada indivíduo associa a um nome, diferentes representações, imagens da fantasia, conhecimentos ou informações anteriores. É o lado "subjetivo", constituído pelas peculiaridades de cada indivíduo, pela sua experiência, pela sua capacidade de compreensão. Mas a essência do significar reside na intenção de significação e não nestas peculiaridades individuais, nas associações intuitivas mais ou menos perfeitas, mais ou menos próximas, mais ou menos adequadas. Todas estas particularidades subjetivas se fundem intimamente com a intenção de significação, de tal modo que a vivência unitária de significação, embora compreenda as diferenciações psicológicas, permanece inalterada. A flutuação inevitável dos atos de significar, que relevam da variedade e multiplicidade desses mesmos atos e das circunstâncias contingentes do discurso, não altera a essência das coisas, nem abala a unidade das significações. Esta flutuação atinge apenas os atos subjetivos, componentes da significação, mas não atinge as próprias significações.

Para Husserl, Bedeutung está para o ato de significar como a species para o indivíduo. Assim, mantém-se a distinção entre o conteúdo psicológico e o lógico das expressões e dos atos expressivos. Cada ato expressivo é individual, e portanto, diferente de caso para caso, repetido inúmeras vezes em diferentes ocasiões. Mas sobre esta multiplicidade ilimitada de experiências individuais, mantém-se o mesmo significado expresso em todas elas, sem que a multiplicação e variedade de pessoas e atos multipliquem os significados proposicionais: por exemplo, o juízo ' $\pi$ é um número transcendental', no sentido ideal, lógico, mantém-se o mesmo e único. ${ }^{19}$

Não é necessário, portanto "ontologizar" a esfera dos sentidos, isto é situá-los num domínio objetivo independente dos respetivos atos significativos; só nos comprometemos com os atos mentais e suas propriedades, que vão desde as representações subjetivas, associações, recordações, etc., até à

17 Cf. LI, I, § 34

${ }^{18}$ Cf. LI, I, $\S 15$, pp. 292-293: Husserl adopta a distinção proposta por Frege, substituindo os termos: Sinn por Bedeutung e este último por 'objeto', ou 'correlato objetivo'.

${ }^{19}$ Cf. LI, I, § 31, p. 329. 
intencionalidade própria de cada ato. Neste aspeto, a teoria de Husserl tem a vantagem da economia ontológica, em relação à tese de Frege, que introduz os sentidos, sobretudo o sentido das proposições, ou seja os pensamentos por elas expressos, como entidades apreendidas por esses mesmos atos e com total independência destes. Em Husserl, cada ato expressivo integra-se na significação objetiva, como uma instanciação desse significado universal.

Em Frege, portanto, não se põe o problema da intencionalidade: a direccionalidade de um ato expressivo não é realizada pelo próprio ato, mas via linguagem (sentido), e todo o uso da linguagem tem de fato o seu sentido. Husserl vê o sentido ou o significado, como uma das partes que integram os atos expressivos, sendo estes instanciações, casos, do significado.$^{20}$ Pelo contrário, Frege situa o sentido como uma entidade significativa entre o ato e o objeto ao qual se refere, ${ }^{21}$ portanto distinto do ato e do seu objeto (ou referente). Assim, o sentido estabelece uma mediação que permite a relação significativa do ato, dirigindo-o para o seu objeto. É esta perspetiva que dá lugar ao problema da "ligação" entre o ato e o objeto referido. Essa "ligação" seria feita pela própria linguagem, que transporta consigo o sentido. E daí a metáfora do "captar", "apreender", que atribui aos atos, não só expressivos, mas aos próprios atos de pensar, uma espécie de simples recetividade de algo que lhe é extrínseco, que não the pertence por direito próprio. Os pensamentos, que não são objetos, mas são o que captamos ao conhecer, não formam parte, não se integram no ato de pensar. A apreensão de um pensamento pressupõe alguém. que o apreenda. Mas este é dono do ato de pensar, mas não do pensamento. ${ }^{22}$ A conhecida 'inexistência intencional do objeto' está totalmente posta de parte, em Frege. Ao contrário da intencionalidade de qualquer nexo entre ato/objeto, em que o "objeto" pode não existir a não ser como algo intencionado, no caso dos atos de pensar, os seus 'objetos', os pensamentos, têm de existir para que se dê o ato de pensar. Por absurdo que pareça, a existência de pensamentos antecede necessariamente os correspondentes atos de pensar, donde se pode concluir a existência de pensamentos jamais pensados. Como afirma Frege, os pensamentos, verdadeiros ou falsos são eternos e independentes do fato de

${ }^{20}$ Mohanty (1982), p. 62, sintetiza a profunda diferença subjacente às teorias de Frege e Husserl: "For Husserl, the meanings are meanings of acts (acts of consciousness), for Frege, they are neanings of signs (linguistic expressions)".

21 Cf. CP 160: "The reference of a proper name is the object itself which we designate by using it. The 'idea' which we have in designating the object is wholly subjective. Between object and 'idea' lies the sense, which certainly is no longer subjective, like the 'idea', but is yet not the object itself." (Sublinhados nossos.)

22 Cf. CP 369. 
serem pensados por alguém; e se for verdadeiro, é verdadeiro independentemente de alguém o reconhecer como verdadeiro. ${ }^{23}$

No entanto, em Ideen I, a noção de noema e noemata é apresentada como corrèlato dos atos mentais, e não já como a espécie universal da qual participam os atos individuais. A noção de noema, constituiria assim um retrocesso, mais próximo da teoria fregeana, com todos os seus pressupostos de estatuto ontológico dúbio e ambivalente? A aproximação entre a noção de noema e a de sentido é pertinente?

A ideia em que Føllesdal se baseia para justificar a aproximação entre Frege e Husserl, nomeadamente entre noema e sentido, assenta no seguinte: Husserl afirma que o noema não é mais do que a generalização da noção de sentido (linguístico), ${ }^{24}$ ampliando-a para todos os atos de consciência, não só os atos expressivos, mas também atos não expressivos. Originariamente empregue na esfera linguística, os termos bedeuten e Bedeutung (significar e sentido) estendem-se a todos os atos e explicam satisfatoriamente o seu carácter intencional, a sua capacidade de dirigir-se, referir-se a um "objeto".

"Originariamente estas palavras, 'significar (bedeuten) e 'sentido' (Bedeutung), relacionam-se só com a esfera do discurso, da 'expressão'. Mas é quase inevitável e ao mesmo tempo um passo importante no conhecimento, estender e modificar convenientemente o sentido destas palavras de modo que, até certo ponto, se possam aplicar a todos os atos, quer envolvam atos expressivos quer não: Empregamos a palavra sentido (Sinn) na sua aceção mais ampla".25

De fato, é necessário "modificar e adaptar convenientemente o sentido destas palavras", - porque o que interessa aqui a Husserl não é tão-só dar conta do significado linguístico, semântico, mas do próprio carácter inten-

${ }^{23}$ Cf. PW 174 e 2 . Frege reconhece que a natureza deste 'visar' ou dirigir-se para dos atos de conhecimento é certamente misteriosa. Referindo-se por exemplo à lei da gravitaçãoo como um caso de 'sentido', pensamento, anota que não somos nós que criamos a lei ao pensa-la, uma vez que ela é verdadeira seja qual for a posição das mentes humanas. Mas, sem dúvida, a apreensão da lei é um processo mental. No entanto, argumenta Frege, é um processo mental confinado ao âmbito do mental, e ao captar a lei, apresenta-se-nos algo cuja natureza não é mental em sentido próprio, ou seja, o pensamento. Por isso se trata de um processo misterioso. Mas, precisamente por ser mental, Frege considera não ser necessário ocupar-se do problema em lógica. É suficiente saber que podemos captar pensamentos e reconhecer que são verdadeiros. Como se dá este processo, é, sem dúvida, um problema a resolver no seu âmbito próprio. Cf. PW 145.

24 Ideen III, 89, 2-4: "O noema não é senão a generalização da noção de significado (Bedeutung ) ao campo de todos os atos. Citado por Føllesdale.

${ }^{25}$ Ideen I, 304, cit. por Føllesdal, "The Notion of Noema", Dreyfus (1982), p. 74. Não cabe aqui uma exposição detalhada sobre a noção de noema em Husserl. Para uma análise da noção de noema no context da teoria do significado, cf. Føllesdale (1990), pp. 263-271. 
cional de todos os atos de consciência, também os que estão pressupostos nos atos expressivos. É necessário ter em conta esta viragem do foco de interesses: para Frege a noção de sentido fora introduzida para justificar o valor cognitivo das proposições de identidade do tipo $a=b$ : Trata-se de propor uma via de mediação que corresponde ao critério de identidade de um mesmo objeto de referência através de diferentes sentidos. Em Husserl, a noção de significado e sentido, é a via para dar conta de como os atos expressivos (e não expressivos) intencionam o respetivo objeto apresentado. Por outras palavras: para Frege, o sentido será inicialmente o modo de explicar como é que o mesmo objeto pode ser visado, referido através de diferentes modos ou diferentes vias; a questão em Husserl parte da consciência e a questão que se lẹvanta é como podem diferentes atos de consciência (expressivos e não expressivos) intencionar uma mesma unidade de sentido, mantendo sempre a sua diversidade e diferença. Isto é, como é que uma perceção, uma crença, um desejo podem visar, na sua diferenciação individual, um mesmo "objeto" de consciência, ou uma mesma unidade de sentido?

$\mathrm{O}$ contexto em que se inserem as duas noções é portanto radicalmente distinto: no primeiro caso, estamos no campo estritamente semântico dọ atos expressivos, dos processos de significação; o segundo integra-se no contexto fenomenológico, centrado na noção de intencionalidade de todos os atos de consciência. O problema da intencionalidade foi o que Frege deixou em aberto, sobretudo no escrito mais tardio Der Gedanke: o pensamento é identificado com o sentido da proposição, mas o carácter intencional do ato de pensar torna-se problemático na relação que Frege estabelece entre este mesmo ato e o pensamento. É uma apreensão, captação, (greifen) que não dá conta da identidade intencional do ato com o seu pensamento, porque em última análise não se trata nunca do seu pensamento, mas de algo extrínseco ao ato que é nele captado. Fica em aberto uma fissura, visto que o pensamento enquanto pensamento - objetivo, intemporal, independente do sujeito que o pensa - não se pode integrar perfeitamente nem muito menos identificar com o próprio ato de pensar. Há uma distância marcada aqui pelo carácter subjetivo do ato e pela objetividade do pensamento. Em Husserl, o noematischer Sinn integra-se na estrutura dos atos de consciência, ou melhor, é a estrutura noemática que explicita a própria intencionalidade dos atos de consciência.

Para ilustrar o problema da diferença de perspetiva Frege/Husserl, invoquemos um conhecido exemplo, proposto por Putnam: é um exemplo um tanto primário e possivelmente demasiado simplista, mas que se pode aproximar, em certa medida, daquilo que se pretende mostrar com este rápido confronto entre as duas teorias do sentido. É o caso da formiga que, andando sobre a areia, traça aleatoriamente uma linha que acaba por se parecer com a caricatura de Winston Churchill. Poderá dizer-se, neste caso que o desenho traçado 
pela formiga retrata, representa Churchill? A formiga nunca viu Churchill nem tinha a intenção de o retratar: limitou-se a traçar uma linha, e mesmo isso não foi intencional, uma linha na qual podemos ver como um retrato de Churchill. A semellhança do desenho com as feições de Churchill não é suficiente para que possa ser considerado como uma representação ou um modo de se referir a Churchill.

O que Putnam se interroga é precisamente sobre as condições necessárias e suficientes para que algo seja uma representação de algo, ou para que algo possa referir-se, significar, ou "estar por" uma outra coisa diferente. E o exemplo ilustra bem que a semelhança não é necessária nem suficiente para constituir algo em signo, representação de algo. Parece que, para se dar uma relação de representação, de referência, torna-se necessária a intenção de representar ou de referir. Mas, para isso, é necessário que antes se seja capaz de pensar nisso que se quer representar ou que se pretende significar. Se as linhas na areia não podem por si mesmos representar coisa alguma, como é que as formas de pensamento poderão em si mesmas representar algo?

Seria excessivo dizer que Frege se coloca ao nível das formigas e dos seus desenhos aleatórios: mas, por vezes parece que os nomes, as proposições têm a capacidade de, por si mesmas, realizar a referência pelo fato de exprimirem um sentido que nos limitamos a captar, como entidades externas a nós e ao nosso pensar. A representatividade dos signos linguísticos está neles próprios, não vem de nós, embora exija a nossa compreensão.

Em Husserl a questão da relação representacional - da passagem ao sentido - é ampliada, transferida para a totalidade dos atos de consciência, sem os quais não há atos expressivos. A intentio pertence, por direito próprio e por inerência, à șignificação, porque todo o ato expressivo a exige.

\section{Referências}

BaR-ElLI, Gilead (1996). The Sense of Reference. Intentionality in Frege. Berlin/New York: De Gruyter.

Burge, Tyler (2005). Truth, Thought, Reason: Essays on Frege. Oxford: Oxford University Press.

CHIsнolm, Robert (1957). Perceiving: A Philosophical Study. Ithaca/New York.

Chisholm, Robert (1952). Intentionality and The Theory of Sign". Philosophical Studies: An International Journal for Philosophy in the Analytic Tradition, 3(4) (June 1952): 56-63.

Couto Soares, Luísa (2001). Conceito e Sentido em Frege. Porto: Campo das Letras. 
Diamond, Cora (1995). The Realistic Spirit. Wittgenstein, Philosophy and the Mind Cambridge Mass./London: The MIT Press.

Dreyfus, Hubert L. (1982). Husserl Intentionality and Cognitive Science. Cambridge Mass.: The MIT Press.

DuMMETT, Michael (1978). Truth and other enigmas. Oxford: Oxford University Press.

Føllesdale, D. (1958). Husserl und Frege: Ein Beitrag zur Beleuchtung der Entstehung der phänomenologischen Philosophie. Oslo: Aschehoug.

Føllesdale, D. (1969). Husserl's Notion of Noema. The Journal of Philosophy, 66: 680-687.

Føllesdale, D. (1990). Noema and Meaning in Husserl. Philosophy and Phenomenological Research, 50, Supplement (Autumn, 1990): 263-271.

FREGE, Gottlob (1952). Translations from the Philosophical Writings of Gottlob Frege (Edited by Peter Geach \& Max Black). Oxford: Basil Blackwell.

FrEGE, Gottlob (1967). Kleine Schriften (Ignacio Angelelli org.). Darmstadt and Hildesheim: Georg Olms Verlag (KS).

Frege, Gottlob (1980). Philosophical and Mathematical Correspondence. Oxford: Basil Blackwell (CP).

Frege, Gottlob (1979). Posthumous Writings. Oxford: Basil Blackwell (PW).

HaAparanta, Leila (ed.) (1994). Mind, Meaning and Mathematics. Essays on the Philosophical Views of Husserl and Frege. Dordrecht/Boston/London: Kluwer Academic Publishers.

Husserd, Edmund (2000). Logical Investigations, trad. J. N. Findlay. Humanity Books.

Husserl, Edmund (1983). Ideas Pertaining to a Pure Phenomenology and to a Phenomenological Philosophy. First Book. Translated by F. Kersten. Dordrecht/ Boston/London: Kluwer Academic Publishers.

Keefe, Ros \& Smith, Peter (1996). Vagueness: a Reader. Cambridge Mass.: The MIT Press.

KEMP, Gary (1996). Frege's Sharpness Requirement. The Philosophical Quarterly, 46(183): 168-184.

Mohanty, J. N. (1982). Husserl and Frege. Bloomington: Indiana University Press.

Ruffino, Marco (2003). Frege's Views on Vagueness. Manuscrito, 26(2): 253-277

Solomon, Robert (1970). Sense and Essence: Frege and Husserl. International Philosophical Quarterly, 10,380.

TrAvis, Charles (1985). Observations and Sorites. Mind, New Series, 94(375): 345-366.

WeINER, Joan (1990). Frege in Perspective. Ithaca/London: Cornell University Press.

Williamson, Ti (1994). Vagueness. Routledge. 


\begin{abstract}
This paper aims to present an approach to Frege and Husserl's theories of meaning in order to integrate meaning in the broader context of intentionality.

Intentionality and reference are two notions with affinities, despite their pertaining to different but not separated areas.

When comparing Frege and Husserl's theories of meaning and intentionality we may provide a fruitful and enriching perspective: some problems and concepts of Husserl's thought may be elucidated if confronted with those of Frege. On the other hand, Husserl's theories of meaning and intentionality provide a broader and far-reaching scope to Frege's ideas on meaning.

Husserl's concept of intentionality provides a new perspective which allows to overcome some of the impasses of Frege's theory of meaning.
\end{abstract}

